\title{
Genetic markers-based genome assembly and the reference genome of the selfing fish Kryptolebias hermaphroditus: Identification of 63 cytochrome P450 genes and the interspecific syntenic comparison
}

\section{Beom-Soon Choi}

Phyzen

Jeonghoon Han

Sungkyunkwan University

Min-Sub Kim

Sungkyunkwan University

Yoshitaka Sakakura

Nagasaki Daigaku

Bo-Young Lee

Sungkyunkwan University

Jae-Seong Lee ( $\nabla$ jslee2@skku.edu )

Sungkyunkwan University https://orcid.org/0000-0003-0944-5172

Research article

Keywords: Genome annotation, Kryptolebias, synteny, linkage group, cytochrome P450

Posted Date: January 22nd, 2020

DOI: https://doi.org/10.21203/rs.2.14108/v2

License: (c) (i) This work is licensed under a Creative Commons Attribution 4.0 International License.

Read Full License 
The authors have withdrawn this preprint from Research Square 